\title{
EFEKTIVITAS PENGGUNAAN E-FILING DALAM RANGKA MENINGKATKAN KEPATUHAN PELAPORAN SURAT PEMBERITAHUAN TAHUNAN WAJIB PAJAK ORANG PRIBADI
}

\author{
Endang Winarsih \\ endangwinarsih@unismuh.ac.id \\ Asyarif Khalid \\ asyarifkhalid@unismuh.ac.id \\ Forene Yenjeni \\ yenjeniforene@gmail.com \\ Fakultas Ekonomi dan Bisnis \\ Universitas Muhammadiyah Makassar
}

\begin{abstract}
In an effort to maximize Taxpayer Compliance, the Directorate General of Taxation always optimizes services so as to increase public awareness of orderliness as taxpayers, one way to do tax reform is to utilize information and communication technology by implementing e-filing systems. This research is a Mix Method research in which research combines two research methods at the same time, qualitative and quantitative. The purpose of this study is to determine the Effectiveness of the Use of EFiling in the Framework of Improving Compliance Reporting the Obligatory Annual Notification of Individuals. The results of this study indicate that the use of e-filing has been successful in increasing the compliance of individual taxpayers by increasing the annual tax return report of individual taxpayers. Taxpayers find it easy to report their annual tax returns by using e-filing. In addition, taxpayers are aware of their obligations as taxpayers. However, there are some obstacles in implementing e-filing, namely the lack of knowledge of taxpayers and the difficulty of convincing taxpayers to use e-filing effectively and efficiently.
\end{abstract}

Key words : e-filing, compliance, taxpayers

\begin{abstract}
Abstrak
Dalam upaya memaksimalkan Kepatuhan Wajib Pajak, Direktorat Jendral Pajak selalu mengoptimalkan pelayanan agar dapat meningkatkan kesadaran masyarakat untuk tertib sebagai wajib pajak, salah satu caranya dengan melakukan reformasi perpajakan yaitu memanfaatkan teknologi informasi dan komunikasi dengan menerapkan sistem $e$-filing. Penelitian ini termasuk penelitian Mix Method dimana penelitian dengan mengkombinasikan antara dua metode penelitian sekaligus, kualitatif dan kuantitatif. Tujuan dari penelitian ini adalah untuk mengetahui Efektivitas Penggunaan E-Filing Dalam Rangka Meningkatkan Kepatuhan Pelaporan Surat Pemberitahuan Tahunan Wajib Orang Pribadi. Hasil penelitian ini menunjukkan bahwa Penggunaan e-filing sudah berhasil dalam meningkatkan kepatuhan wajib pajak orang pribadi melalui meningkatnya angka pelaporan SPT Tahunan wajib pajak orang pribadi. Wajib pajak merasakan kemudahan dalam melaporkan SPT Tahunannya dengan menggunakan $e$-filing. Selain itu, wajib pajak menyadari akan kewajibannya sebagai wajib pajak. Namun terdapat beberapa Kendala dalam penerapan e-filing yaitu kurangnya pengetahuan wajib pajak maupun sulitnya meyakinkan wajib pajak akan penggunaan $e$-filing yang efektif dan efisien.
\end{abstract}

Kata Kunci: E-filing, Kepatuhan, Wajib paja 


\section{PENDAHULUAN}

Indonesia yang merupakan Negara berkembang membutuhkan sebuah pembangunan guna menjadi Negara yang lebih maju. Menurut Soemitro (2011:2) mengemukakan definisi Pajak sebagai peralihan kekayaan dari pihak rakyat kepada kas Negara untuk membiayai pengeluaran rutin dan surplusnya digunakan untuk public saving yang merupakan sumber utama untuk membiayai public investment. Pajak juga dapat diartikan iuran wajib yang bersifat memaksa masyarakat melalui proses peralihan kekayaan kepada pemerintah untuk membiayai pengeluaran rutin Negara dengan imbalan secara tidak langsung (Akib dan Amdayani 2017).

Direktorat Jenderal Pajak melakukan salah satu perubahan yaitu dengan melakukan perbaikan proses bisnis yaitu memanfaatkan teknologi informasi dan komunikasi dengan menerapkan electronic filing system atau E-Filing. Melalui Keputusan Direktur Jenderal Pajak Nomor Kep-88/PJ/2004 pada bulan Mei tahun 2004 secara resmi diluncurkan produk E-Filing. Tepatnya pada tanggal 24 Januari 2005 bertempat di Kantor Kepresidenan, Presiden Republik Indonesia bersamasama dengan Direktorat Jenderal Pajak meluncurkan produk E-Filing. E-filing merupakan layanan pengisian dan penyampaian Surat Pemberitahuan Wajib Pajak yang dilakukan secara elektronik melalui sistem online yang realtime kepada Direktorat Jenderal Pajak melalui internet pada website Direktorat Jenderal Pajak atau melalui Penyedia Jasa Aplikasi yang telah ditunjuk oleh DJP. Dengan diterapkannya sistem E-Filing, diharapkan dapat memberikan kenyamanan dan kemudahan bagi Wajib Pajak dalam mempersiapkan dan menyampaikan Surat Pemberitahuan (SPT) karena dapat dikirimkan kapan saja dan dimana saja sehingga dapat meminimalkan biaya dan waktu yang digunakan Wajib Pajak untuk penghitungan, pengisian dan penyampaian SPT. E-filing dapat meminimalkan biaya dan waktu karena hanya dengan menggunakan komputer yang terhubung internet, penyampaian SPT dapat dilakukan kapan saja yaitu selama 24 jam sehari dan 7 hari dalam seminggu (termasuk hari libur) dan dimana saja tanpa perlu datang ke kantor pajak untuk memberikannya pada Petugas Pajak (Akib dan Amdayani 2017).

\section{TINJAUAN PUSTAKA}

\section{a. Pengertian $E$-filing}

Menurut Akib dan Amdayani (2017) Pengertian penerapan menurut Kamus Besar Bahasa Indonesia adalah proses cara, perbuatan menerapkan; pemasangan; pemanfaatan. E-filing merupakan bagian dari sistem dalam administrasi pajak yang digunakan untuk menyampaikan SPT secara online yang realtime kepada kantor pajak. Jadi, penerapan sistem e-filing adalah suatu proses atau cara memanfaatkan sistem yang digunakan untuk menyampaikan SPT secara online yang realtime yang diterapkan oleh Direktorat Jenderal Pajak.

1. Alur penggunaan E-Filing Menurut Avianto et.al (2016:4) Adapun alur penggunaan $E$-Filing diantaranya:

a) Menggunakan aplikasi e-Reg untuk mendapatkan NPWP

b) Mengajukan permohonan e-FIN dengan datang langsung ke KPP terdekat dan e-FIN akan diberikan langsung kepada wajib pajak. 
c) Melakukan registrasi sebagai wajib pajak pengguna $e$-filing .

d) Menyampaikan SPT melalui e-filing

e) Mengisi e-SPT pada aplikasi $e$-filing

f) Meminta kode verifikasi untuk pengiriman e-SPT yang akan dikirimkan melalui email yang sudah didaftarkan

g) Mengirim SPT secara online dengan mengisikan kode verifikasi

h) Notifikasi status e-SPT dan bukti penerimaan elektronik akan diberikan kepada wajib pajak melalui email yang sudah didaftarkan.

\section{b. Pengukuran Kepatuhan Perpajakan}

1. Pengertian Kepatuhan Wajib Pajak

Menurut Akib dan Amdayani (2017) Wajib Pajak adalah subyek pajak yang terdiri dari orang pribadi atau badan yang memenuhi syarat-syarat obyektif yang ditentukan oleh UndangUndang, yaitu menerima atau memperoleh penghasilan kena pajak yang mempunyai hak dan kewajiban perpajakan sesuai dengan ketentuan peraturan perundang-undangan. Subyek pajak adalah orang atau badan yang bertempat tinggal atau berkedudukan di Indonesia. Objek pajak menurut UU No. 36 Tahun 2008 pasal 4 tentang pajak penghasilan berbunyi yang menjadi objek pajak adalah penghasilan yaitu setiap tambahan kemampuan ekonomis yang diterima atau diperoleh Wajib Pajak, baik yang berasal darri Indonesia maupun luar Indonesia, yang dapat dipakai untuk konsumsi atau untuk menambah kekayaan Wajib Pajak yang bersangkutan, dengan nama dan dalam bentuk apapun Kepatuhan perpajakan dapat didefinisikan sebagai keadaan dimana Wajib Pajak memenuhi semua kewajiban perpajakan dan melaksanakan hak perpajakannya (Rahman, 2010) sedangkan menurut Nasucha (2004), Kepatuhan Wajib Pajak dapat diidentifikasi dari Kepatuhan Wajib Pajak dalam mendaftarkan diri, kepatuhan untuk menyetorkan kembali Surat Pemberitahuan, kepatuhan dalam penghitungan dan pembayaran pajak terutang dan kepatuhan dalam pembayaran tunggakan. Jadi, Kepatuhan Wajib Pajak adalah ketika Wajib Pajak memenuhi semua kewajiban perpajakan dan melaksanakan hak perpajakannya, kewajiban perpajakan meliputi mendaftarkan diri, menghitung dan membayar pajak terutang, membayar tunggakan dan menyetorkan kembali surat pemberitahuan.

a. Elemen- Elemen Kepatuhan Perpajakan Kepatuhan sebagai fondasi self assessment dapat dicapai apabila elemen- elemen kunci telah diterapkan secara efektif. Elemen- elemen kunci (Ismawan, 2001:83) tersebut adalah sebagai berikut.

a) Program pelayanan yang baik kepada wajib pajak.

b) Prosedur yang sederhana dan memudahkan wajib pajak.

c) Program pemantauan kepatuhan dan verifikasi yang efektif.

d) Pemantapan law enforcement secara tegas dan adil.

Ada dua macam kepatuhan, yaitu kepatuhan formal dan kepatuhan material. Kepatuhan formal adalah suatu keadaan di mana wajib pajak memenuhi kewajiban secara formal sesuai dengan ketentuan dalam undang- undang perpajakan. Kepatuhan material adalah suatu keadaan di mana wajib pajak memenuhi semua ketentuan material perpajakan, yakni sesuai dengan isi dan 
jiwa undang- undang perpajakan. Kepatuhan material dapat juga meliputi kepatuhan formal.

\section{METODE PENELITIAN}

\section{a. Metode Analisis}

Metode analisis yang digunakan dalam penelitian ini adalah metode Mix Method (Kualitatif-Kuantitatif) yang menggambarkan dan menjelaskan hasil dari rasio kepatuhan wajib pajak selama 3 tahun sebelum dan 3 tahun sesudah diterapkannya sistem e-filing. Rasio kepatuhan tersebut dihitung dengan menggunakan rumus sebagai berikut:

\section{HASIL DAN PEMBAHASAN}

\section{a. Hasil Penelitian}

Penerapan Layanan E-Filing Dalam Pelaporan SPT Tahunan Sebagai Upaya Meningkatkan Kepatuhan Wajib Orang Pribadi

\section{Pelaksanaan Penerapan Layanan $\boldsymbol{E}$ - Filing Dalam Pelaporan SPT Tahunan Orang Pribadi.}

Latar belakang adanya layanan $e$ filing adalah terkait proses penerimaan, pengolahan, dan pengarsipan SPT yang panjang dan memakan waktu yang lama serta pentingnya inovasi berbasis teknologii untuk menuju administrasi perpajakan yang lebih baik. Ada beberapa cara pelaporan SPT Tahunan yang dapat dilakukan oleh wajib pajak, pertama dapat diberikan secara langsung baik ke kantor pelayanan pajak dan atau ke tempat lain seperti pojok pajak, drop box, dan mobil pajak. Kedua secara tidak langsung melalui kantor pos, perusahaan ekspedisi (dengan bukti pengiriman surat ke KPP tempat wajib pajak terdaftar). Ketiga secara online yaitu wajib pajak menggunakan aplikasi $e$ - filing, yakni memanfaatkan teknologi informasi penyampaian SPT Tahunan dapat dilakukan secara elektronik, secara online dan realtime melalui internet.

Pelaksanaan penerapan layanan $e$ filing di KP2KP Bontosunggu dilaksanakan mulai tahun 2016, 2017, 2018 hingga sekarang. Direktorat Jendral Pajak selalu berusaha untuk membuat pengadministrasian perpajakan menjadi lebih baik. Dapat diketahui bahwa dengan adanya e-filing proses pelaporan yang dilakukan oleh wajib pajak menjadi lebih sederhana, mudah, praktis, cepat dan efisien.

\section{Peningkatan Kepatuhan wajib pajak orang pribadi.}

Kepatuhan dalam memenuhi kewajiban perpajakan merupakan tulang punggung sistem self assessment. Wajib pajak bertanggungjawab menetapkan sendiri kewajiban perpajakan dan kemudian secara akurat dan tepat waktu membayar dan melaporkan pajak tersebut. Kepatuhan dalam bidang perpajakan menurut Safri Nurmanto dalam Siti Kurnia Rahayu (2010:138) mengatakan bahwa kepatuhan perpajakan dapat dapat didefinisikan sebagai suatu keadaan dimana Wajib Pajak memenuhi semua kewajiban perpajakan dan melaksanakan hak perpajakannya.

Data yang digunakan dalam penelitian ini adalah data sekunder. Data tersebut meliputi jumlah WPOP yang menggunakan formulir $1770 \mathrm{~S}$ dan 1770SS yang terdaftar di KP2KP Bontosunggu dari tahun 2013 sampai dengan tahun 2018 serta jumlah penerimaan SPT Tahunan PPh WPOP formulir 1770 S dan 1770 SS di KP2KP 
Bontosunggu dari tahun 2013 sampai dengan tahun 2018

Jumlah WPOP yang terdaftar dari tahun 2013-2018

\begin{tabular}{||l||l||l||l||l|}
\hline \hline No. & $\begin{array}{l}\text { Tahun } \\
\text { Pajak }\end{array}$ & $\begin{array}{l}\text { WPOP } \\
\text { Terdaftar }\end{array}$ & $\begin{array}{l}\text { WPOP } \\
\text { Efektif }\end{array}$ & $\begin{array}{l}\text { WPOP tidak } \\
\text { Efektif }\end{array}$ \\
\hline \hline 1 & 2013 & 330.220 & 327.045 & 3.175 \\
\hline \hline 2 & 2014 & 343.287 & 338.712 & 4.575 \\
\hline \hline 3 & 2015 & 345.446 & 339.718 & 5.728 \\
\hline \hline 4 & 2016 & 351.807 & 345.811 & 5.996 \\
\hline \hline 5 & 2017 & 358.787 & 351.722 & 7.065 \\
\hline \hline 6 & 2018 & 359.793 & 352.236 & 7.557 \\
\hline
\end{tabular}

Sumber: Data KP2KP Bontosunggu 2019 (diolah)

Berdasarkan tabel 4.1 di atas Jumlah Wajib Pajak yang terdaftar di Kantor Pelayanan dan Konsultasi Perpajakan Bontosunggu mengalami peningkatan dari tahun ke tahun. Adanya peningkatan ini berarti merupakan tanda bahwa jumlah pelaporan SPT Tahunan dari Wajib Pajak yang mendaftarkan diri sebagai Wajib Pajak akan memiliki kewajiban perpajakan salah satunya melaporkan SPT Tahunannya.

Menurut Surat Edaran Direktur Jenderal Pajak nomor SE26/PJ.2/1988 tentang Kriteria WP Efektif dan WP Non Efektif, pengertian Wajib Pajak Efektif adalah Wajib Pajak yang memenuhi kewajiban perpajakannya dengan memenuhi kewajiban menyampaikan Surat Pemberitahuan (SPT) Masa dan/atau Tahunan sebagaimana mestinya. Sedangkan Wajib Pajak Non Efektif adalah Wajib Pajak yang tidak memenuhi kewajiban perpajakannya. Dan sedangkan Wajib Pajak terdaftar merupakan wajib pajak yang telah mendaftarkan diri pada Kantor Pelayanan Pajak dan telah memiliki Nomor Pokok Wajib Pajak (NPWP). Wajib Pajak yang terdaftar tidak semua memiliki kewajiban untuk menyampaikan SPT PPh.
Ada Wajib Pajak yang dikecualikan dari kewajiban menyampaikan SPT PPh, yaitu Wajib Pajak Pajak Penghasilan tertentu. Menurut Peraturan Menteri Keuangan No. 183/PMK.03/2007 tentang Wajib Pajak Pajak Tertentu yang Dikecualikan dari Kewajiban Menyampaikan Surat Pemberitahuan Pajak Penghasilan.

\section{Kepatuhan Wajib Pajak Sebelum Penerapan Sistem E-Filing

$$
\text { Pada kantor Pelayanan }
$$

Penyuluhan dan Konsultasi Perpajakan Bontosunggu, kesadaran wajib pajak atas kewajiban pembayaran pajaknya masih sangat kecil, namun SPT yang diterima oleh KP2KP bontosunggu setiap tahunnya tetap mengalami peningkatan. Hal tersebut menunjukkan bahwa kesadaran wajib pajak akan kewajiban pajaknya sudah mulai mengalami peningkatan sehingga dapat meningkatkan kepatuhan wajib pajak. Data statistik dibawah ini menunjukkan perkembangan kepatuhan wajib pajak pada KP2KP Bontosunggu selama tiga tahun sebelum penerapan e-filing sebagai berikut:

Tabel 4.2

Kepatuhan Wajib Pajak Sebelum Penerapan Sistem E-Filing

\begin{tabular}{||l||l|l||l|l||}
\hline \hline No. & Tahun Pajak & WPOP Terdaftar & $\begin{array}{l}\text { SPT yang di } \\
\text { Lapor }\end{array}$ & $\begin{array}{l}\text { Rasio } \\
\text { Kepatuhan }\end{array}$ \\
\hline \hline 1 & 2013 & 330.220 & 275.232 & $83,34 \%$ \\
\hline \hline 2 & 2014 & 343.287 & 289.141 & $84,22 \%$ \\
\hline \hline 3 & 2015 & 345.446 & 299.112 & $86,58 \%$ \\
\hline
\end{tabular}

Sumber: Data KP2KP Bontosunggu 2019 (diolah)

Berdasarkan Tabel 4.2 di atas dapat diketahui bahwa total penerimaan SPT Tahunan PPh orang pribadi yang direkap selama tiga tahun sebelum diterapkannya sistem e-filing mengalami peningkatan yang sejalan dengan meningkatnya jumlah Wajib Pajak setiap tahunnya. Pada tahun pajak 2015 tercatat Wajib Pajak yang terdaftar 
sebanyak 345.446 orang dan sebanyak 299.112 Wajib Pajak yang melaporkan SPT Tahunannya pada KP2KP Bontosunggu sehingga nilai Kepatuhan Wajib Pajak mencapai 86,58\% Rasio kepatuhan Wajib Pajak tersebut juga mengalami peningkatan disetiap tahunnya. Namun secara mayoritas, masih terdapat banyak Wajib Pajak Orang Pribadi yang tidak melaporkan SPT Tahunannya pada KP2KP Bontosunggu. Hal tersebut disebabkan karena masih kurangnya kesadaran masyarakat akan pentingnya pajak bagi Negara.

\section{b. Pembahasan Penelitian}

E-filing adalah suatu proses atau cara memanfaatkan sistem yang digunakan untuk menyampaikan SPT secara online yang realtime yang diterapkan oleh Direktorat Jenderal Pajak. Dalam upaya memaksimalkan kepatuhan wajib pajak, Direktorat jendral Pajak selalu mengoptimalkan pelayanan agar dapat meningkatkan kesadaran masyarakat untuk tertib sebagai wajib pajak, salah satu caranya dengan melakukan reformasi perpajakan yaitu memanfaatkan teknologi informasi dan komunikasi dengan menerapkan sistem e-filing .

Pada tahun 2018 tingkat kepatuhan wajib pajak pada KP2KP Bontosunggu mengalamii peningkatan. Hal tersebut di karenakan tingkat kesadaran wajib pajak mulai tumbuh dan menyadari akan pentingnya pajak bagi perekonomian Negara. Direktorat jendral pajak semakin bertegas dan memberikan tekanan yang keras agar wajib pajak lebih patuh dalam melaporkan kewajibannya.
Pada Kantor Pelayanan dan Konsultasi Perpajakan Bontosunggu melaporkan jumlah SPT Tahunan Pph WPOP setelah penerapan e-filing mengalami peningkatan dibandingkan jumlah penyampaian SPT Tahunan Pph WPOP sebelum penggunaan e-filing. Peningkatan jumlah WPOP Terdaftar semakin besar dibandingkan dengan peningkatan jumlah WPOP yang melaporkan SPT Tahunannya dengan menggunakan sistem e-filing melalui Website DJP. Penerapan sistem e-filing dalam laporan SPT Tahunan pada KP2KP Bontosunggu dapat dikatakan telah efektif.

Pada tahun 2016 kontribusi WPOP yang melaporkan SPT Tahunannya yang menggunakan sistem e-filing melalui Website DJP sebesar 85,24\% atau setara dengan 299.898 orang. Pada tahun 2017 kontribusi WPOP yang melaporkan SPT Tahunannya yang menggunakan sistem e-filing mengalami peningkatan sebesar $87,97 \%$ setara dengan 315.657 orang. Dan pada tahun pajak 2018 juga mengalami peningkatan menjadi 89,02\% atau setara dengan 320.289 orang.

Kepatuhan wajib pajak dapat didefinisikan sebagai kesadaran untuk memenuhi kewajiban agar mengisi formulir pajak dan menghitung sendiri jumlah pajak yang terutang dengan benar. Berdasarkan hasil penelitian yang dilakukan oleh peneliti penggunaan sistem e-filing di KP2KP Bontosunggu sudah berjalan dengan baik karena wajib pajak dapat merasakan adanya kemudahan dalam penyampaian SPT Tahunan dengan alasan menghemat biaya dan waktu. 
Penelitian ini sejalan dengan penelitian yang dilakukan oleh Avianto, et.al., (2016) yang menyatakan bahwa pelaksaan e-filing sudah cukup berhasil dalam meningkatkan kepatuhan melalui meningkatnya angka penyamapaian SPT Tahunan Wajib Pajak Orang Pribadi. Dan banyak pula wajib pajak yang merasakan lebih praktis, mudah, cepat dan efisien dengan menggunakan $e$-filing

Hal ini menandakan ada peningkatan dalam kepatuhan wajib pajak orang pribadi. Menurut peneliti wajib pajak yang menggunakan e-filing dalam pelaporan SPT Tahunannya memiliki tingkat kepatuhan yang lebih tinggi atas kewajiban penyampaian SPT Tahunannya dibandingkan dengan wajib pajak yang menggunakan manual.

Melalui $e$-filing wajib pajak dapat melaksanakan kewajibannya dalam hal ini pelaporan SPT Tahunan dengan praktis, mudah, cepat, dan efisien. $E$ filing dapat menumbuhkan suatu kepatuhan sukarela bagi wajib pajak melalui program pelayanannya yang baik dan prosedur yang sederhana serta memudahkan wajib pajak, wajib pajak dapat terbantu dalam memenuhi kewajiban perpajakan sebagai bentuk kepatuhan. Dengan meningkatnya angka pelaporan SPT Tahunan wajib pajak orang pribadi maka dapat menggambarkan peran dari e-filing dalam meningkatkan kepatuhan.

\section{PENUTUP}

\section{a. Simpulan}

Berdasarkan dari penelitian yang telah dilakukan, maka dapat disimpulkan sebagai berikut:

1. Berdasarkan hasil penelitian yang telah dilakukan, menunjukkan bahwa penerapan sistem e-filing di KP2KP Bontosunggu Kabupaten Jeneponto berjalan dengan baik. Hal ini bisa dilihat dari laporan SPT Tahunan wajib pajak yang tiap tahunnya mengalami peningkatan.

2. Penerapan $e$-filing berpengaruh positif terhadap Kepatuhan Wajib Pajak di KP2KP Bontosunggu Kabupaten Jeneponto. Penerapan sistem e-filing sangat bermanfaat bagi Wajib Pajak, baik dalam hal kecepatan pelaporan SPT, kehematan dalam pelaporan, tidak merepotkan, kemudahan dalam pelaporan SPT. Hal ini berarti semakin tinggi penerapan sistem e-filing maka semakin tinggi kepatuhan wajib pajak

\section{b. Saran}

1. KP2KP Bontosunggu Kabupaten Jeneponto diharapkan Lebih mengoptimalkan dan memaksimalkan sistem informasi untuk mengembangkan aplikasi e-filing itu sendiri.

2. KP2KP Bontosunggu Kabupaten Jeneponto diharapkan Lebih meningkatkan sosialisasi yang dilakukan kepada wajib pajak dengan cara memberikan pemahaman tentang penggunaan $e$-filing ataupun pemberian pemahaman tentang hak dan kewajiban sebagai wajib pajak.

3. Untuk peneliti selanjutnya diharapkan untuk mengkaji lebih banyak sumber maupun referensi yang terkait dengan Efektivitas Penggunaan e-filing agar hasil penelitiannya dapat lebih baik dan lebih lengkap lagi. 


\section{Daftar Pustaka}

Abdurrohman, S. 2015. Implementasi Program E-Filing Dalam Upaya Peningkatan Kepatuhan Wajib Pajak Orang Pribadi (Studi pada Kantor Pelayanan Pajak Pratama Bojonegoro). Jurnal Administrasi Publik, 3(5),807-811.

Akib, M., \& Amdayani, L. 2017. Analisis Penerapan Sistem E-Filing Dalam Menyampaikan Surat Pemberitahuan (SPT) Wajib Pajak Orang Pribadi (Studi pada KPP Pratama Kendari). Jurnal Akuntansi dan Keuangan, 1(1).

Avianto, G. D., Rahayu, S. M., \& Kaniskha, B. 2016. Analisa Peranan E-Filing Dalam Rangka Meningkatkan Kepatuhan Pelaporan Surat Pemberitahuan Tahunan Wajib Pajak Orang Pribadi (Studi pada Kantor Pelayanan Pajak Pratama Malang Selatan). Jurnal Mahasiswa Perpajakan, 9(1).

Bayangkara, IBK. 2017. Audit manajemen Prosedur dan Implementasi. Jakarta: Salemba Empat.

Dyanrosi, A. 2015. Analisis Perilaku Wajib Pajak Orang Pribadi Terhadap Minat Perilaku Menggunakan E-Filing. JISIP: Jurnal Sosial dan Ilmu Politik,4(2). Http://www.maxmanroe.com/vid /umum/penelitian-kualitatif.html Http://www.pajak.go.id/artikel/in klusif-inovatif-wujudkan-kp2kpyang-transformatif

Kurniati, D. H., Susilo, H., and Mukzam, M.D. 2016. Pengaruh Pengetahuan Perpajakan dan kualitas Pelayanan terhadap Kesadaran Wajib Pajak dalam Menyampaikan Surat Pemberitahuan(spt) Tahunan (Studi pada Kpp Pratama Blitar). Jurnal Mahasiswa Perpajakan, 9(1).

Marliana, R., Suherman, M., \& Almunawwaroh, M. 2017.
Pengaruh Penerapan E-Filing Terhadap Kepatuhan Wajib Pajak dalam penyampaian Surat Pemberitahuan (SPT) Tahunan pada Kantor Pelayanan Pajak Pratama Kota Tasikmalaya. Media Riset Akuntansi, Auditing \& Informasi, 15(1), 49-64.

Novarina, A. 1. 2005. Implementasi Electronic Filing System (E-Filing) Dalam Praktik Penyampaian Surat Pemberitahuan (SPT) Di Indonesia (Doctoral Dissertation, Program Pasca Sarjana Universitas Diponegoro.

Nurlaela, L. 2018. Pengaruh Penerapan E-Filing Terhadap Kepatuhan Wajib Pajak pada KPP Pratama Garut. Journal Wahana Akuntansi, 2(2)

Oktariyanti, G. K. (2018). Penggunan System Aplikasi E-Filing Dalam Pelayanan Perpajakan Terhadap Kepatuhan Wajib Pajak Pada Kantor Pelayanan Pajak Pratama Baturaja Dalam Perspektif Hukum Ekonomi Syari'ah (Doctoral dissertation, fakultas syariah dan hukum).

Purwono, Herry. 2010. Dasar-Dasar Perpajakan \& Akuntansi Pajak. Jakarta: PT Gelora Aksara Pratama.

Resmi, Siti. 2013. Perpajakan teori dan kasus. Edisi 6, Jakarta: Salemba Empat.

Sari, N. A., Bandang, A., \& Rura, Y. (2013). Analisis Kepatuhan Wajib Pajak atas Penyampaian SPT masa PPN dengan Penerapan Elektronik (eSPT) di kantor Pelayanan Pajak Makassar Utara. Skripsi. Fakultas Ekonomi dan Bisnis Universitas Hasanuddin Mkassar.

Soekirman, A., Rachmany, H., \& Happy, V. V. (2018). Analisis Implementasi Kebijakan Sistem Electronic Filing sebagai upaya menngkatkan 
Kepatuhan Wajib Pajak dalam Penyampaian Surat Pemberitahuan Tahunan kepada KPP Pratama Tangerang Barat Tahun 2013,2014, dan 2015. Jurnal ilmiah untuk Mewujudkan Masyarakat Madani, 5(2), 174-184.

Supadmi, N. L. 2009. Meningkatkan Kepatuhan Wajib Pajak Melalui Kualitas Pelayanan. Jurnal Ilmiah Akuntansi Dan Bisnis. 